\title{
REALIDADES COLECTIVAS EN EL ARTE ESPAÑOL DE LA DÉCADA DE 1980
}

Introducing modal aesthetics

\author{
Jorge Luis Marzo \\ Centro Universitario de Diseño Bau (Barcelona) - \\ Grupo de Investigación gredits (Grupo \\ de Investigación en Diseño y Transformación Social).
}

RESUMEN: En contraposición al relato académico oficial del arte contemporáneo español durante la década de 1980, que ha fomentado una lectura individualista y genialista de las prácticas artísticas de entonces, es fácilmente comprobable que una gran parte de las mismas se condujo mediante vertebraciones colectivas y grupales. El presente texto analiza aquellas modalidades de gestión y conceptualización creativas y plantea la idea de fondo de que lo que hoy constituye una forma extensa de ideación, gestión, producción y difusión cultural - la práctica del colectivo - estaba ya presente en los debates artísticos de los años inmediatamente posteriores a la transición política.

Palabras Clave: colectivos, historia del arte en España, década de 1980, transición.

RESUM: En contraposició al relat acadèmic oficial de l'art contemporani espanyol durant la dècada de 1980, que ha fomentat una lectura individualista i genialista de les pràctiques artístiques de llavors, és fàcilment comprovable que una gran part de les mateixes es va conduir mitjançant vertebracions collectives i grupals. El present text analitza les modalitats de gestió i conceptualització creatives i planteja la idea de fons que el que avui constitueix una manera extensa d'ideació, gestió, producció i difusió cultural — la pràctica del col·lectiu—, estava ja present en els debats artístics dels anys immediatament posteriors a la transició política.

1. Una parte sustancial del presente texto forma parte de la obra: Marzo J. L.; Mayayo, P. (2015): Arte en España 1939-2015. Ideas, prácticas, políticas. Madrid: Cátedra. ISBN: 978-84-376-3483-8. Reproducida con el permiso de la editorial Cátedra. 
Paraules Clau: col·lectius, història de l'art a Espanya, dècada de 1980, transició.

ABSTRACT: In contrast to the official academic account of contemporary Spanish art during the 1980s, which has fostered an individualistic and genius-oriented reading of the artistic practices of those times, it can be easily verified that much of the work was produced through collective and group structures. This paper analyzes those creative management and conceptualization models and suggests that current cultural models of ideation, management, production and dissemination of collective practices were already present in artistic debates during the years immediately following Spain's political transition to democracy.

KEYWORDs: collectives, art history in Spain, 1980s, spanish political transition.

\section{Introducción}

El relato que se tejió del carácter y la actitud de los artistas de los años ochenta premió una visión individualista que indudablemente partió de muchos de los comportamientos de los propios creadores de entonces. De entre las numerosas declaraciones y manifestaciones que podemos encontrar en las hemerotecas, acaso por la relevancia comercial y mediática del artista vale la pena resaltar las del pintor Miquel Barceló en 1984:

Para mí la tradición española es la que veo en El Prado. Es una tradición de pintor español que da la sensación de estar siempre ensimismado, metido en su taller [...] Lo que yo entiendo por pintura española es una tradición muy kamikaze y toda esa cosa como más gregaria me hace desconfiar muchísimo [...] Tal vez en el año cuarenta estuviera bien que se juntaran cinco o seis pintores para hacer algo de tipo informalista, entonces tuvo un sentido pero ahora me parece un sinsentido total. Una especie de institucionalización de pequeños planetas de poder con su corte de acólitos, eso me produce absoluta repulsión. Así que la tradición española que yo escojo, por supuesto, es la fatal. (Rubio, 1991:114) 
Convenientemente, Barceló se hacía heredero de una narración individualista que lo emplazaba en una apropiada genealogía nacionalista. Por sus palabras, podríamos deducir que lo colectivo es antinatural a la historia del arte español y que, además, lo colectivo se define como una mera estrategia de defensa de los propios intereses. Barceló, por otra parte, obviaba que la mayoría de pintores cuya obra está presente en el Prado habían trabajado en estructuras colectivas de taller, y que de kamikazes tenían poco, pues la mayor parte de ellos estuvieron al servicio de la Corte.

Los réditos de este tipo de actitudes eran diáfanos bajo la luz arrojada por un mercado que perseguía la firma como motor de expansión y como marca de una sociedad libre surgida tras la transición. Jesús Carrillo ha señalado atinadamente que:

[...] el «arte libre» de la democracia no se produjo por la disolución y atomización del impulso hegemónico partidista en narraciones y prácticas heterogéneas, sino por un proceso de naturalización y normalización ideológica de carácter no menos hegemónico que implicaba, esencialmente, la consagración de un artista de individualidad marcada que produjera artefactos fácilmente mercantilizables y que, falto de toda agencia o voluntad de autonomía, se pusiera a merced absoluta del poder económico y político de turno. (Carrillo, 2007:25)

En esta dirección, cabe señalar el ejemplo del artista Ferrán García Sevilla, originariamente procedente de la escena conceptual catalana, quien en una conversación con otros artistas en 1989 defendió sin ambages ni aparente asomo de ironía la individualidad radical, el producto puro y duro y el hacerse rico: «Ah, sois muy moralistas. Si es muy simple. Es necesario ganar dinero. Yo necesito el máximo posible. Así de simple» (Brea, 1992:176).

Sin embargo, tanto este tipo de posicionamientos individualistas como los resultados manifiestamente rentables que produjeron no pueden ocultar que una parte también importante de las prácticas creativas de los años ochenta se resolvieron por caminos grupales, asociativos y colaborativos cuyos objetivos diversos poco tenían que ver con la consecución de vínculos con una historia oficialista tanto del arte como de los artistas, o con la defensa de intereses meramente mercantiles, cuando para muchos de los grupos y colectivos que surgieron en la década el asociacionismo y la interdependencia eran no 
sólo un formato de trabajo sino una apuesta por la transformación del espacio operativo y proyectivo del arte.

\section{Definiciones}

Tan sólo recientemente, los historiadores (ver bibliografía) han empezado a prestar atención a esta innegable realidad, oscurecida por el afecto del mercado al genialismo indómito y por la desaprensión institucional ante las actividades grupales, siempre difíciles de gestionar política y académicamente, siempre pasto de comportamientos de aparente disenso. Muchas de las interpretaciones que se han elaborado sobre el carácter y modo de interpretar el tejido asociacionista del arte español pasan por la definición de lo «alternativo», de lo «independiente». Ello se debe a una extendida sospecha entre la periferia cultural de que lo hegemónico en la Institución Arte pasa por tres ejes centrales: la autoría, la plusvalía y la estetización. El cuestionamiento de estos pivotes ha marcado las tradicionales definiciones de lo alternativo, que, a su vez, proceden de algunas de las problematizaciones más enérgicas del discurso moderno y de vanguardia: la muerte del autor, explorada por autores ya clásicos como Michel Foucault o Roland Barthes, o desde una perspectiva ácrata por Agustín García Calvo; el rechazo paralelo a la etiquetación profesional, estilística o disciplinar, que congela matices, hibridaciones y fugas; los principios de mediación que confieren al producto artístico la cualidad de fetiche, de singularidad y de exclusividad, un tema ampliamente expuesto por las diferentes escuelas marxistas, desde los principios analizados por Walter Benjamin o la Escuela de Frankfurt; o la superación de los espacios de mediación codificados artísticamente - museos y galerías - que obligan a que los productos culturales sean percibidos únicamente en clave estética (un contradiscurso central en las prácticas de estela situacionista pero también conceptual de los años sesenta y setenta).

La definición de lo alternativo en el arte español de los años ochenta pasa, además, por dos factores significativos. Por un lado, la contracultura de la década anterior, ya estuviera ligada a la oposición antifranquista o a los comportamientos micropolíticos. Por otro lado, el tema de la financiación pública. La deriva de ambos factores bajo el relato de la transición y de la aparente normalización de las condiciones productivas de la cultura ocasionó que la 
interpretación de lo independiente cobrara formas hasta cierto punto hipocondríacas. La centralidad operada por las nuevas entidades culturales públicas, legitimadas en el nuevo orden democrático y asumidas por una gran parte de los productores culturales, despertó temores entre los actores menos entusiastas de los modelos sociopolíticos imperantes de quedar sumidos en una marginalidad ineficaz, al tiempo que impidió un análisis profundo de las relaciones, causas y efectos entre la financiación pública y la independencia de gestión, función y objetivos de los grupos autoconsiderados autónomos. Por todo ello, la definición y configuración de los colectivos y grupos, entendiendo éstos dentro de un discurso elástico que se mueve entre la necesidad de fondos institucionales y la defensa de modos y públicos propios, ha sido manifiestamente difícil. Pedro Garhel, fundador del Espacio P en Madrid en 1981, se preguntaba: «¿Alternativo a qué? Alternativo a nada. Simplemente fue lo que tenía que ser en el momento que era necesario» (Aramburu, 2010:18).

La institucionalización del arte efectuada por las administraciones surgidas de la transición y la globalización de la mediación cultural como forma rápida de inserción geopolítica añadieron complejidad a la hora de definir conceptos como «alternativo», a la vez que alimentaron sospechas sobre su verdadero carácter contrahegemónico. En ese sentido, vale la pena citar un texto de José Luis Brea - acaso excesivamente pesimista a causa de un probable desinterés por ciertas prácticas radicales-, en el que expresaba lo que, en su opinión, dificultaba la medición de lo alternativo en la escena nacional:

Todo espacio pretende serlo [alternativo] y casi ninguno lo es. Los más conspicuos herederos de la escuela frankfurtina en New York han denunciado el progresivo desplazamiento de lo alternativo a la función antes reservada a lo museístico. Así, sería ahora el espacio alternativo el convocado a otorgar a la obra registro de validez pública y derecho de ingreso al sistema de la historia. Dicho de forma más directa: que lo alternativo también se ha 'institucionalizado', absorbido por el sistema de manera que su continua invocación empieza a resultar tediosa e irrelevante. Como ejercicio, podríamos imaginar un sistema en que 'todo' fuera tan 'alternativo' que lo realmente difícil fuese encontrar el 'a qué'. Tal vez en sistemas de esa índole lo alternativo sería lo normalmente 'normal'. (Aramburu, 2010:7)

Paralelamente, la incapacidad de las administraciones para reflexionar apropiadamente sobre las condiciones de lo público se constata en el hecho 
de haber establecido una enorme patrimonialización en el ámbito de la subvención cultural, sin percibir el carácter «común» que la institución debe proyectar para ser realmente pública; además de tratar con desdén, cuando no con abierto rechazo, aquellas prácticas sociocreativas más radicales que en Bilbao, Madrid, Sevilla, Valencia o Barcelona operaban completamente al margen de la administración. Tampoco los espacios formativos, a priori potenciales nodos de expansión colectiva y alternativa, conformaron apenas ninguna opción frente a los modelos hegemónicos. Miren Eraso y Carme Ortiz han apuntado que:

[...] en los espacios dedicados a la formación no se produjo una reforma importante ni modernización real de sus marcos ideológicos, ni curriculares ni de organización. Este hecho tendrá lugar tanto en el espacio de investigación universitaria como en el más propio de la creación de las Escuelas de Arte, que llegarán progresivamente a convertirse en espacios anacrónicos y poco representativos [...]. (Eraso, Ortiz, 2007:119)

Sin embargo, gracias en parte a las conexiones internacionales operadas por algunos grupos de los ochenta y a la experiencia adquirida a principios de los noventa por cientos de jóvenes productores culturales que habían conocido de primera mano modelos de gestión independiente en países como Estados Unidos, Canadá, Alemania, Holanda, Inglaterra o Francia - fruto de las becas otorgadas durante la década anterior-, pudo articularse con los años las relaciones entre independencia y administración con algo más de claridad. En este sentido, hay que señalar que toda una generación de artistas y gestores volvieron entonces con ideas frescas sobre la articulación de espacios autónomos y de modelos de gestión artística alternativos a los oficiales, además de sobre las propias experiencias creativas.

Una de aquellas primeras aportaciones nacidas del contacto con otros modelos exteriores la elaboró Tere Badia en 1992 en un texto de gran interés titulado El hecho $X$. De lo alternativo a los alterespacios, publicado al año siguiente en la revista barcelonesa De Calor. Según Badia, lo alternativo se define por su inaprensibilidad, por la fuerza de su constante mutabilidad:

[Lo alternativo] es motor de una actividad constante que en el encuentro con los afines actúa como espoleta de arranque de una acción determinada, la 
cual después se mueve rápidamente hacia otro lugar, pues sus conceptos base se encuentran en continuo desplazamiento. Y junto a ello, la desaparición de los roles establecidos, la imposibilidad de compartimentar la cultura y la creación, la anomia ante el calificativo o el clasificativo. Una situación de constante inaprensibilidad.

Al mismo tiempo, Badia planteaba el encaje de lo individual en lo colectivo:

El nacimiento de muchas de estas iniciativas responde a la voluntad individual de actuar en la creación de una conciencia colectiva [...] el hecho mismo de que sea una opción personal plantea la postura del individuo respecto a los problemas del entorno, entendido éste como aquel lugar de los grandes movimientos de masas donde todo queda diluido. Esta intención de intervenir en las representaciones y lenguajes ideológicos de la vida diaria hace que el artista, más que un productor de objetos, devenga también un manipulador de signos [...] La obra realizada de dicha manera incide en el contexto - físico, político y social— desde donde y hacia donde está hecha. (Badia, 1993:12-13)

Estos nuevos puntos de partida, aunque no acabaron de ser del todo aprovechados durante los noventa a la hora de vertebrar los tejidos locales, más allá de manifestaciones puntuales y a menudo efímeras, sí que formaron parte del nacimiento de nuevas redes a mediados de la década.

\section{Pervivencia y desarrollo del colectivo}

A la hora de redactar una concisa historia del asociacionismo en el arte español, no se pueden obviar los pasos dados por grupos de artistas durante los años setenta, con el objetivo de establecer plataformas de carácter sindical, que articularan un espacio de defensa colectiva de las condiciones productivas, laborales y jurídicas de la profesión. A comienzos de los ochenta, Cataluña marcó el paso con la constitución en 1980 de la Federación Sindical de Artistas Plásticos de Cataluña, después refundada en la Asociación de Artistas Visuales de Cataluña. Al poco tiempo, bajo el impulso de la federación catalana, se unieron las asociaciones de Madrid, Aragón, Castilla y León, Baleares, Galicia y algunas andaluzas de ámbito provincial, englobadas todas 
bajo la Confederación Sindical de Artistas Plásticos (CSAP), presidida por el pintor Eduardo Arenillas. El CSAP organizó en 1988 el Congreso Estatal de Artes Plásticas, que tendrá lugar en el Centro Reina Sofía, siendo un año después la anfitriona de la Asamblea General de la International Artists Association (IAA-UNESCO). Sin embargo, la CSAP morirá pronto de inanición, teniendo que ser refundada en 1996 en la Unión de Asociaciones de Artistas Visuales (UAAV), contando ya con la presencia añadida de las asociaciones de Euskadi, Valencia y Navarra (Guntín, 2010).

Abundantes han sido los debates y discusiones sobre el papel de estas asociaciones en el desarrollo profesional del tejido artístico español. La gran dependencia de las subvenciones públicas, por lo demás habitual en el entramado general de los sindicatos, ha mostrado en ocasiones la endeblez del propio tejido asociativo, que no puede mantenerse con las simples cuotas de los socios. Tampoco ha sido inhabitual escuchar a los artistas manifestar su desapego a fórmulas asociativas en las que creían percibir actitudes políticas que consideraban contrarias a un dominio supuestamente libre de cortapisas como el arte. Las asociaciones de artistas han ejercido a menudo como pequeños lobbies de presión en ámbitos como los derechos de los artistas a la vinculación profesional y jurídica que comporta un contrato, los derechos sobre la obra y la difusión de su imagen, la necesidad de hacer públicos y transparentes los procedimientos de gestión institucional, sus presupuestos, o el nombramiento de cargos. Han asesorado a numerosos artistas en procesos legales y han fomentado la creación de redes y el establecimiento de unas infraestructuras de formación y producción más que las meramente promocionales o de difusión. Precisamente a causa de estas dinámicas de inserción y homologación de la práctica artística en las regulaciones profesionales, las funciones de las asociaciones de artistas han sido percibidas por algunos sectores creativos como caballos de Troya de un proceso institucionalizador que impedía la expansión de modelos alternativos a los promovidos por las administraciones públicas, además de desactivar una crítica política más amplia y una extensión social de la defensa de los derechos laborales que fuera más allá de las demandas estrictamente sectoriales del arte. Un ejemplo más de las querelles de fondo ideológico que lo independiente o lo alternativo han cosechado en España. 
En paralelo al tejido asociativo sindical, en los años ochenta surgieron numerosas iniciativas creativas de carácter colectivo. La mayoría de ellas se configuraron alrededor de espacios o de actitudes que tenían como eje una gran interdisciplinariedad de formatos: poesía visual, pintura, escultura, accionismo, performance, fotografía, cine, video, instalación, nuevos medios, actividades formativas. Al mismo tiempo, muchas de ellas se distinguían por la voluntad de crear redes de intercambio y circulación. Repasemos algunas de ellas

En buena medida, las periferias alejadas de Madrid y Barcelona marcaron el ritmo del surgimiento de colectivos en el cambio de década a principios de los años ochenta. Muestra de ello son, por ejemplo, Taller Lunàtic (19751982), grupo surgido en Palma de Mallorca y encabezado por Josep Albertí, Steva Terrades y Bartomeu Cabot, dedicado a la edición fancinera - cuya obra más destacada fue la revista Neon de Suro, inspirada en parte por una revista visual como Blanc d'Ou (1977-1978)—, a la poesía visual, al arte postal, al cómic, a la ilustración y a la pintura, y en el que participaron artistas como Miquel Barceló, Lluís Juncosa, Eugènia Balcells, Javier Mariscal o Toni Catany. Taller Lunàtic tendría derivas individuales posteriores, algunas bien singulares, como la obra literario-visual de Jaume Sastre Freixura de porc o Incitació a la intolerancia (1983).

En 1981, surgía en Reus (Tarragona) el grupo SIEP (Sàpigues i Entenguis Produccions, hasta 1984), que animarán el arte postal junto a otros colectivos nacionales e internacionales, e iniciarán una larga serie de actividades editoriales, musicales y artísticas. En opinión de Francesc Vidal, uno de los principales impulsores del colectivo, la intencionalidad del grupo pasaba por crear una plataforma de difusión de la producción individual de cada miembro, pero, al mismo tiempo, por buscar estrategias ultralocalistas «a fin de convertir el resto en periferia». ${ }^{1}$

A mediados de la década se formó en Zaragoza el Sindicato de Trabajadores Imaginarios (STI), bajo la coordinación de Javier Cinca. Dedicados a la edición musical independiente, editaron un fanzine/revista artístico-musical llamada Particular Motors, y colaboraron extensamente con grupos de arte

1. Declaraciones de Francesc Vidal a J. L. Marzo, noviembre de 2013. 
postal. En breve, STI se convirtió en la mayor distribuidora de material industrial sonoro y experimental de la década. Su catálogo de venta por correo ofrecía una fabulosa cantidad de discos, casetes, fanzines y vídeos, además de compilaciones de poesía sonora internacional.

Otro ejemplo de las sinergias en las consideradas «periferias geográficas» fue la fundación del colectivo A Ua Crag (contracción de «agua crujiente») en Aranda de Duero (Burgos), en 1985. Integrado inicialmente por Alejandro Martínez Parra y Rafael Lamata, dos alumnos y colaboradores cercanos de Pedro Garhel, se sumarían al grupo Julián Valle, Jesús Max, Pepe Ortega, Miguel Cid, Néstor San Miguel, Javier Ayarza y Rufo Criado. Colectivo de larga duración (se disolvería en 1996), lograría a principios de los años noventa su mayor intensidad gracias a toda una serie de intercambios y colaboraciones con otros grupos de Bélgica, Alemania, Holanda o Canadá; producciones que empezaban y finalizaban a menudo en su espacio de la Fábrica Moradillo de Aranda de Duero.

Durante los años ochenta, y también en Castilla-León, surgieron grupos como el Frente Idiota (1982-1984), de carácter marcadamente contracultural, con Luis Marquina, Vórtex, Kraker, Rafa Madrazo, Guedio, y grupos musicales como Incidentes Genuinos y Pepillo. Juntos editaron fanzines, y realizaron acciones de arte urbano y performances. Se formaron asimismo S.C.R.N.A.B. (Burgos, 1986-1987), Espacio Tangente (Burgos, anteriormente El Afilador), El Apeadero (León), Monográfico (desde 1987), La voz de mi madre (Salamanca-Valladolid-Badajoz) o Alén (Soria, 1992-1994), formado por Carlos Sanz Aldea e Ignacio Caballo. Monográfico, «colectivo de una sola persona» (Luan Mart), realizó una intensa labor tras la revista homónima, impulsando multitud de eventos, performances, vídeos y distintas publicaciones (Trigueros, 2010:84).

A principios de los años ochenta, en lo que podría llamarse «periferias culturales» de las grandes ciudades, surgieron un número de espacios que catalizaron toda una serie de actividades asociativas. En Barcelona, en 1980, la Sala Metrònom, propiedad del empresario y coleccionista Rafael Tous, inició su andadura en un pequeño local de la calle Berlinés antes de ocupar la espléndida sala del Born durante su segunda etapa. Metrònom fue otro de los primeros «espacios independientes» de la ciudad, alrededor del cual gravi- 
taron durante años muchísimos artistas, ideas y proyectos. Algunas galerías y salas catalanas ya habían fomentado a finales de los años setenta formatos asociativos y colaborativos alejados de los usos más habituales en este tipo de espacios: las Galerías G y Aquitània, la Petita Galeria de Lleida, la sala Vinçon, la Escuela Eina, la galería Ciento. También en localidades como Granollers (G-57), Hospitalet, Banyoles, Bellaterra (Espai B5-125) o Sabadell (Sala Tres), el tejido asociacionista en las prácticas artísticas tenía recorrido gracias al poso dejado por la escena conceptual.

En 1981, nace en Madrid el Espacio P, fundado por el artista canario Pedro Garhel en el sótano de una sastrería en el centro de la ciudad. Garhel ya procedía de experiencias colectivas en los años setenta, concretamente del Grupo Corps. El Espacio P, considerado por algunos como el primer espacio alternativo español de la década — de extensa longevidad, hasta 1997—, desarrolló actividades en campos muy variados: poesía visual (con Javier Maderuelo, Julio Campal, Felipe Boso, José Antonio Sarmiento...), arte postal, vídeo y performance (formatos que veremos en las secciones correspondientes), instalaciones, cursos y talleres, y siempre con una gran conectividad nacional e internacional. En 1989, Acindino Quesada convocó desde la Fundación Danae de París un encuentro internacional de espacios independientes que abrían un nuevo proceso en torno a la producción artística, y en el que el Espacio P tuvo un notable protagonismo. Entre 1985 y 1990, el espacio contó con la participación activa de Karin Ohlenschläger en el ámbito del vídeo y las publicaciones, y cuyos ejes conceptuales fueron el germen del futuro MediaLab Madrid impulsado por ella y Luis Rico en 2002. Otros espacios similares nacieron también en la capital. Victoria Encinas y Luis García Castro montaron Poisson Soluble (1984-1985), un local que quería ser heredero de los espacios surrealistas y dadaístas de vanguardia, y en el que tuvieron lugar actividades de música, arte postal, artes plásticas, cine, y performances. El espacio abrió sus puertas con dos proyectos de espacio público, Autobús y Consumo cotidiano.

En 1987, el grupo Inicio, formado por Concha Jerez, Darío Corbeira y Francisco Felipe, recibió la invitación a participar en uno de los eventos paralelos de la Documenta de Kassel, el K18 Group Art Work, lo que les dio a sus miembros la ocasión de conocer experiencias colectivas internacionales y 
articular nuevos modos de producción comisarial más horizontales. A partir de ese año surgen múltiples festivales o jornadas de vídeo y performance en las que primó muchas veces el carácter colectivo de las producciones y de la gestión. Aquellos eventos tuvieron lugar en locales como bares y espacios alternativos de Madrid; en Chueca, en el Espacio P, en Centros Okupados, en El Ojo Atómico o en el espacio Válgame Dios bajo impulso de Nieves Correa y Tomás Ruiz Rivas entre 1990 y 1991. Manifestó Ruiz Rivas respecto a aquellas actividades:

Los festivales fueron importantes porque crearon un fuerte sentimiento de comunidad artística. Su carácter absolutamente marginal, la libertad creativa, la intensidad y amplitud de su base social, la participación de decenas de voluntarios fueron determinantes para la conceptualización y el desarrollo de proyectos como El Ojo Atómico. (Aramburu, 2010:23)

Aparecen también grupos vinculados a la universidad, como Laboratorio de la Luz en la Universidad Politécnica de Valencia en 1986, coordinado por José María Yturralde, y en el que participaron, en diversas formas y fases, Emilio Martínez, Maribel Domenech, Salomé Cuesta, Trinidad García o María José Martínez de Pisón, siempre en el ámbito de las investigaciones de luz y color. También en Valencia surge ANCA (Associació de Nous Comportaments Artístics), en 1990, a partir del interés de Bartolomé Ferrando y un grupo de estudiantes en el arte de acción. Por su parte, La Voz de mi Madre, una asociación de artistas ácratas constituida en 1989, cuyo fin era «usar el arte como agitación en contra del aburrimiento», se formó en el seno de la Escuela de Artes y Oficios Artísticos de Valladolid por Ana Manteca, Félix Orcajo, Jesús Sánchez y Carlos TMori, desarrollando posteriormente sus actividades en la Facultad de Bellas Artes de Salamanca. El colectivo reclamaba y ocupaba espacios urbanos infrautilizados, además de editar el fanzine Los Avisos. Serían numerosos los grupos que participaron en los diversos proyectos realizados: TIaTE (Jesús Portal, Carlos TMori); Hutto (Mercedes Cardenal, Jesús Portal, Carlos TMori, Carlos Salas, Francisco José Prieto, Miguel Ángel Cortés, Miguel Ángel S. Nicolás, Angelina Antolín, Juan Ramón Fernández y Javier Díez); y Los cien acres del diablo (Orcajo y Diego Prieto Pigazo) tanto en Salamanca, Valladolid u Olmedo (Valladolid). 
En la facultad madrileña de Bellas Artes surge ese año Libres para Siempre, con Almudena Baeza, Beatriz Alegre, Alberto Cortés, Miguel Ángel Martín, Álvaro Monje, Ana Parga y María Luz Ruiz, que realizaron la primera exposición inaugural de Estrujenbank. Allí conocerían a otros colectivos como EMPRESA, integrado por Javier Montero y Ángel y Pablo San José, que llevaban a cabo un hiperrealismo «narro-punk» con una gran complicidad en los aspectos colaborativos, y que se suma a los grupos de intervención artística como Agustín Parejo School, Preiswert Arbeitskollegen-Sociedad de Trabajo no Alienado, Estrujenbank (Pintura y Hojalatería en General), o Grupo Surrealista de Madrid; y a los colectivos más abiertamente vinculados a la performance o al accionismo como Circo Interior Bruto (J. M. Giró y Jaime Vallaure) (Baeza Medina, 2005).

La muestra Madrid, espacio de interferencias (1990) presentó, a su vez, una radiografía sobre los residuos de la movida, los colectivos artísticos y espacios alternativos en la precariedad. En 1992, surge Paralelo Madrid, de mano de Llorenç Barber, o El Caballito que es puesto en marcha por Jana Leo, Pedro López Cañas y Agustín Martín Francés en su estudio de la calle Desengaño, que se unen a otros espacios como Cruce o Vaticano. El Caballito se planteó con el solo fin de producir un lugar de encuentros: todos los miércoles había un actividad dirigida a un público reducido: charlas, Súper 8, video, fotografía. Ese mismo año aparece en Barcelona, bajo la dirección de Xavier Sabater, La Papa Multimedia, con la intención de reunir a los poetas «sonoros», en una especie de actualización del Café Voltaire. La Barcelona postolímpica - a veces, contraolímpica - daría frutos muy activos y regeneradores como el colectivo La Porta de coreografía y danza contemporánea, Barcelona Taller, Conservas, Gràcia Territori Sonor, De Calor o La Fàbrica de Cinema Alternatiu.

En Valencia, Ulises Pistolo Eliza abría El Purgatori (1991-1999), en donde tuvo cabida todo lo oriental, lo esotérico, la magia, el simbolismo o el espiritualismo. Las primeras exposiciones con Jorge Yaya, Santi Barber, Olga Freixes, Chema López, Juan Domingo, Alberto Ruiz, o Karen y Mortimer fueron claramente esa dirección; posteriormente, tuvieron gran influencia las tertulias de Nilo Casares, Manuel Monleón, Oscar Mora y Xavier Monsalvatge. 
En Murcia, se constituyó en 1992 el colectivo Mestizo, compuesto por Arena Teatro (artes escénicas), Joaquín Cánovas (cine), Ángel Haro (artes plásticas), Paco Martín (música) y Paco Salinas (fotografía). Se desarrollaron exposiciones, talleres, debates, representaciones escénicas, performances, conciertos, ciclos de cine, videoinstalaciones y publicaciones. El grupo era en parte heredero del Colectivo Imágenes, creado en 1978 por ocho fotógrafos: Antonio Ballester, Juan Ballester, Toni Escolar, Saturnino Espín, Ángel F. Saura, Pepe Pina, Paco Salinas y Ricardo Valcárcel, quienes realizaron una labor reivindicativa de la fotografía y del arte en general como herramienta de la cultura y del desarrollo social, y que, además, ayudó a establecer intercambios con otras ciudades de la provincia como Cartagena - en la que pronto surgió un grupo similar, AFOCAR-, y con ciudades como Córdoba, Madrid, Palma de Mallorca y Valencia (Salinas, 2010:71). Cabe recordar en el ámbito fotográfico la experiencia del Centro Internacional de Fotografía de Barcelona (1978-1983), impulsado originalmente por Albert Guspí, que reunió en su seno a toda una serie de debates y producciones colectivas sobre la función fotográfica durante la transición política. ${ }^{2}$

En el ámbito de la imagen en movimiento, también surgen numerosos grupos a caballo del cambio de década hacia los años noventa: Leona, Bosgarren Kolektiboa, Corrent Alterna, Grupo 3TT, La Turquía del Vídeo, La 12 Visual, ovNI, además de las escuelas gallegas de la imagen Centro Galego das Artes da Imaxe, la Escuela de Imagen y Sonido y el Departamento de Audiovisuales de la Facultad de Bellas Artes de la Universidad de Pontevedra, que favorecerán la formación y producción asociada.

Por parte de algunas entidades de carácter oficial también se desplegaron iniciativas colectivas o con el objetivo de sumar sinergias individuales a fin de redefinir espacios y dinámicas en aquel momento obsoletos. En 1983, el Ministro de Cultura, Javier Solana, solicitó ayuda a la Asociación de Artistas Plásticos a fin de reconducir la deriva del Círculo de Bellas Artes de Madrid, que entonces tenía funciones cercanas a las de un mero casino. Desde la Asociación se promovió la creación de un nuevo proyecto de gestión y de difusión del arte contemporáneo. El Círculo transformó su estructura, con Martín Chi-

2. Ver Ribalta. J.; Zelich. C. (coms.) (2011): Centre Internacional de Fotografia. Barcelona (1978-1983). Catálogo de exposición. Barcelona: MACBA. 
rino como presidente y una Junta Directiva formada por Pedro García Ramos, Marisa González, Francisco Calvo Serraller, Lucio Muñoz, Rafael Canogar, Juan Genovés, José Luis Fajardo, María Montero, Concha Hermosilla, Carlos San Román, Tomás Marco, José Luis Temes, Josefina Molina, Mario Camus, Basilio Martín Patino, Fermín Cabal, Jesús Campos y José Badía. Bajo este impulso y mucho trabajo de voluntariado se iniciaron los primeros Talleres de Arte Actual y Festivales de vídeo.

En 1985, la Muestra de Arte Joven, producida por el Instituto de la Juventud y dirigida por Félix Guisasola, dio pie a que numerosos creadores pudieran entablar contactos mutuos a la vez que fomentó un tímido interés público hacia la creación producida por colectivos. Por su parte, el centro de arte Arteleku, en San Sebastián, creado en 1987 y dependiente de la Diputación de Guipúzcoa, articuló un modelo transversal de colaboración dando cobijo a diversas actividades colectivas y grupos. Ese mismo año, la Fundació Phonos, creada en 1974 en Barcelona por J. M. Mestres Quadreny, Andrés Lewin-Richter y Lluís Callejo, y durante muchos años único estudio de música electroacústica de España, trasladó su estudio situado en un pequeño local del barrio de Sarrià a los sótanos de la Fundació Miró. También en 1987 se inauguraba el Centre d'Iniciatives i d'Experimentació per a Joves (CIEJ) con el que la Fundación «la Caixa» quiso dar respuesta a las inquietudes tecnológicas de jóvenes creadores catalanes. En 1992, será clausurado. En estos dos últimos espacios, diferentes grupos pudieron desplegar sus actividades, fundamentalmente vinculadas a las nuevas tecnologías.

Los colectivos tendrán, a su vez, un gran predicamento en el activismo y los debates feministas. En 1980 se funda el Seminario de Estudios de la Mujer en la Universidad Autónoma de Madrid; más tarde lo hace el Centre d'Investigació Històrica de la Dona de la Universidad de Barcelona (1982). En 1986 surge el seminario Dona i Cultura de Masses, y dos años más tarde el Grup de Geografia i Gènere de la Universidad Autònoma de Barcelona. En 1988 le sigue el Seminario de Investigaciones Feministas de la Universidad Complutense de Madrid y los respectivos Seminarios de Estudios de la Mujer de las universidades de Valencia, Granada y Málaga. Ya en los años noventa, se produce un gran renacimiento de los colectivos feministas como 
LSD, Erreakzioa, o los grupos formados por Helena Cabello y Ana Carceller, o Marta de Gonzalo y Publio Pérez Prieto.

El movimiento okupa, o más exactamente los Centros Sociales Okupados Autogestionados (CSOA), supuso también un modelo de discurso y actividad colectiva que impregnó parte de las dinámicas asociativas de la década, vinculado a propuestas alternativas de sociabilidad, entramado urbano y creatividad, a menudo en sintonía con micropolíticas relativas al ecologismo o al antimilitarismo. La okupación en España ya estaba presente en décadas anteriores como práctica habitual de distintos colectivos como los gitanos. En el ámbito político-sindical, la CNT (Confederación Nacional del Trabajo ) había okupado a finales de los años setenta distintos locales sindicales que no les habían sido devueltos tras el advenimiento de la democracia. También en aquellos años se producen okupaciones de campos improductivos en Andalucía por parte del soc (Sindicato de Obreros del Campo) a fin de autogestionarlas, así como diversos colectivos vecinales inician procesos de empoderamiento urbano en Mallorca, Madrid y Barcelona con el objetivo de alojar a familias necesitadas, y se forman casales okupas con proyectos socioeducativos y creativos en Pamplona y Barcelona, que alcanzarán su auge hacia 1984.

La primera actividad okupa en España con gran repercusión tuvo lugar en Gallecs (Barcelona) en 1978, cuando más de 8000 personas optaron por la creación de una ciudad ecológica y autosostenida en los terrenos que debían albergar un fallido proyecto urbanístico público de ciudad satélite. A partir de 1979 y coincidiendo con el declive del movimiento vecinal organizado, se producen okupaciones por todo el Estado (especialmente en Barcelona, Madrid, Zaragoza, Sevilla, Bilbao o Málaga), teniendo como protagonistas a familias organizadas y asociaciones vecinales, que okupan viviendas. El País Vasco será uno de los territorios en donde estas dinámicas se visualizarán con más intensidad, con casi dos mil okupaciones de viviendas de protección oficial y de la Obra Sindical del Hogar-Ministerio de la Vivienda durante los primeros años ochenta, además de la creación de numerosos centros culturales okupados en Vitoria y Bilbao, que desplegaron numerosas actividades creativas (música, talleres plásticos, ciclos de video y cine, performances). 
A mediados de la década, el boom de la okupación es manifiesto. En Madrid, la okupación en 1987 de Amparo 83, en el barrio de Lavapiés, tuvo el apoyo de las asociaciones de vecinos, de la vecindad del barrio e incluso de un departamento de juventud de la Comunidad de Madrid. Los medios de comunicación oficiales le prestaron gran atención e incluso, durante sus diez días de duración, hasta que fue desalojado por la policía, se llevaron a cabo visitas de colegios al centro social okupado. Tras este desalojo se creó la primera Asamblea de Okupas de Madrid, que promovió tentativas de okupación a lo largo de la década, siendo la más notoria la de Arregui y Aruej, una fábrica abandonada del Puente de Vallecas, que duraría tres meses, y la de Minuesa, en 1988, que duraría seis años. Entre 1991 y 1993, se produjeron como mínimo veinte okupaciones reivindicadas públicamente a lo largo del Estado, tanto en las ciudades ya citadas como en nuevos entornos (A Coruña, Ourense, Granada, Valencia, Alicante, Vigo, Las Palmas, Gijón, Burgos, Santiago de Compostela, Elche o Cáceres). Recordar, por último, que la okupación no-violenta no se constituyó como delito en la legislación vigente hasta 1996, cuando el nuevo Código Penal aprobado en las Cortes incluyó la insumisión al servicio militar y la okupación como actividades ilegales. En ese momento se comienzan a traspasar los conflictos derivados de la okupación de inmuebles de la jurisdicción civil a la penal. ${ }^{3}$

No podemos tampoco dejar de señalar la impronta que los modelos asociacionistas tuvieron en el tejido social por la defensa de los derechos de los homosexuales y lesbianas en todo el territorio. El surgimiento durante los años ochenta de numerosas entidades se catalizó en 1992 con la constitución de la Federación Estatal de Lesbianas, Gays, Transexuales y Bisexuales (FELGTB). Un año antes, una escisión de Colectivo Gay de Madrid (COGAM) llevó a la creación de la Radical Gay, un grupo combativo, antisistema y muy beligerante contra la Iglesia Católica y contra la política sanitaria respecto al

3. Sobre la historia de la okupación en España, ver:

Martínez, M. (2002): Okupaciones de viviendas y centros sociales. Autogestión, contracultura y conflictos urbanos. Barcelona: Virus. Del mismo autor, (2004): «Del urbanismo a la autogestión: una historia posible del movimiento de okupación en España».

Adell, R.; Martínez, M. (coords.) (2004): ¿Dónde están las llaves? El movimiento okupa: prácticas y contextos sociales. Madrid: La Catarata. 
sida. La aparición del VIH-SIDA a mediados de los años ochenta, y la afrenta social y mediática junto a la indolencia inicial de las administraciones públicas en la aplicación de políticas de información, prevención y tratamiento, conllevaron el auge de modelos de activismo colectivo que en algunos casos hicieron suyos formatos de experiencias similares en otros contextos internacionales y que adoptaron formatos artísticos o gráficos como vehículos de sus actividades: Col.lectiu Lambda (Comunidad Valenciana, 1986), Stop Sida (Barcelona, 1986), Act Up (Barcelona, 1989), Actua (Barcelona, 1991), LSD (Madrid, 1993), entre otros. También cabe destacar los distintos proyectos impulsados por Pepe Miralles en Valencia: Proyecto Primero de Diciembre surgía en 1991, formado por profesores, estudiantes y artistas de la Facultad de Bellas Artes, que abogaban por un activismo artístico-político que criticara la representación social que había adquirido la enfermedad del sida y cómo los medios públicos permanecían impasibles ante ella, creando campañas que, en muchos casos, venían a reafirmar esta situación. Asimismo, el proyecto planteaba la necesidad de acabar con la marginación y la humillación que sufren los enfermos. Además de campañas de pancartas emplazadas en algunos de los principales museos de Valencia, en 1992 se organiza una importante exposición en la galería Visor. En 1996, Miralles también impulsa el Colectivo Local Neutral, y junto a María Jesús Talavera, funda el Comité Ciudadano Anti-sida de la Comunidad Valenciana a partir de una experiencia de talleres centrados en la creatividad, la reinserción social y la búsqueda de empleo. ${ }^{4}$

\section{Algunas conclusiones a dos décadas vista}

Las experiencias colectivas de la década de 1980 aquí descritas muestran cómo - en paralelo a la construcción de una narrativa artística individualista y mercantil, efecto de una concepción cultural vinculada a políticas artísticas públicas y privadas que fomentaron el fenómeno artístico como un vehículo

4. Para una descripción de las actividades y objetivos de estos y otros grupos anti-sida en España, ver MARTín HeRnÁNDEZ, R. (2010): El cuerpo enfermo: arte y VIH/SIDA en España. Tesis doctoral. ISBN: 978-84-693-9492-2. Madrid: Universidad Complutense, pp. 295-329. 
de «normalización» liberal y desideologizada en el periodo de la transición—, se produjo un conjunto de fenómenos sociales que abogaban por continuar algunas de las prácticas grupales procedentes de la década de 1970, y que generalmente compartían una perspectiva desautorizadora de la función habitualmente otorgada al arte. Aquellas prácticas se definían mayoritariamente por cuestionar un concepto endogámico del arte y formulaban una cuestión que, con los años, ha acabado siendo central en estos debates: la necesidad de percibir e investigar las metodologías artísticas como instrumentos destinados a insertarse en una esfera exterior, o en todo caso, más amplia que la meramente artística. Tal y como Patricia Mayayo ha analizado con gran precisión, a partir de mediados de la década de 1990 una parte importante de las prácticas artísticas desarrolladas en España se han conducido bajo la condición de disponer los dispositivos artísticos a manera de utensilios de activismo social y político, en su gran mayoría estructurados en formatos colectivos y asociativos (Mayayo, 2015). Esos procesos no hicieron más que continuar, expandiéndolos, modos de hacer ya presentes en algunas de las escenas creativas de la década anterior, muy a menudo invisibilizadas en su día por una estructura de poder y relato que premiaba una supuesta tradición «ensimismada» del proceso artístico como forma de deshacer los discursos críticos producidos bajo una cultura altamente politizada como la del tardofranquismo.

La paulatina adopción de metodologías artísticas por parte de colectivos y entidades con fuertes compromisos sociales y políticos, cuya orientación no se encamina al sistema disciplinar del arte, junto al incremento de prácticas realizadas por artistas cuya funcionalidad es dirigida a ámbitos y objetivos no estéticos han creado nuevas categorías de lo colectivo en el ámbito de la creatividad, que comportan la necesidad de generar nuevos instrumentos de comprensión e interpretación.

En 2007, sugerí la importancia de una actitud de «sociabilidad comprometida» para interpretar con cierta propiedad lo que constituye un factor, en mi opinión determinante, de la fusión de instrumental estético pero orientado a actuar en dominios extraestéticos bajo formatos colectivos. Definía con aquel término aquellas «prácticas desarrolladas en espacios sociales que generan una comunidad de miembros con compromisos mutuos: espacios que 
resultan en efectos comunes y no meramente individuales» (Marzo, 2007:34). No obstante, hoy cabe precisar o matizar esa proposición. La expansión y éxito social de las «industrias digitales y del conocimiento», fundamentalmente vinculadas a la elaboración y comercialización de sistemas de interfaz, videojuegos, aplicaciones, servicios digitales, etc., han venido acompañadas de múltiples relatos sobre la efectividad y productividad estéticas, a menudo planteados como superación del arte contemporáneo definido como disciplina. Al mismo tiempo, estas nuevas industrias han tomado prestadas del dominio artístico toda una batería de conceptos, tanto de índole «vanguardista» (creatividad, innovación, investigación, riesgo...) como de naturaleza metodológica (comunidad, equipo, taller, laboratorio....). El desplazamiento semántico de la idea de colectivo artístico (como hemos visto, muchas veces de evidente proyección social) a colectivo empresarial (start-ups, medialabs...) —con todos sus grados de concomitancias y lejanías respecto a sus respectivos objetivos finales-, reduce en parte la aplicabilidad estrictamente «socioartística» de la noción de «sociabilidad comprometida». Pues, efectivamente, en los nuevos entornos empresariales de creatividad digital, la condición de «compromiso mutuamente dependiente y de efectos comunes» también es aplicable. A menudo, en estos espacios del «cognitariado» digital, las apelaciones a conceptos de incidencia, inserción y transformación social son habituales mediante referencias a la sostenibilidad, accesibilidad e igualitarismo. Acaso, el mejor ejemplo sea el universo industrial asociado a la creación de las smart cities, en el que colectivos de jóvenes emprendedores digitales proyectan la construcción de un modelo de comunidad suprademocrática sustentado no ya por la toma de decisiones sobre el ámbito de la vida pública sino por la accesibilidad y usabilidad de los signos de la misma.

La noción de «comunidad», por consiguiente, parece plantearse hoy como factor eficiente de crecimiento productivo en el ámbito de las nuevas industrias culturales vinculadas al mercado digital. Este proceso de reconceptualización de lo colectivo en el empresariado cultural aparentemente se conduce tomando prestadas ideas y argumentos nacidos en el ámbito tanto del arte como de la prácticas sociales, muchas de ellas surgidas o formuladas durante los años 1980. Sin embargo, esta absorción es equívoca. En realidad, 
debe más al sistema de trabajo en grupo modelado por los entornos científicos, como los laboratorios, que a las premisas mucho menos productivistas que surgieron en los entornos artístico-sociales durante décadas anteriores. Aquellas premisas sugerían una voluntad crítica respecto a la función de lo productivo en la economía política; un aspecto habitualmente ausente en los discursos de la nueva «emprendeduría» tecnocultural. Esta condición, esencial para distinguir el carácter de los desplazamientos aquí señalados, fue agudamente analizada por el artista Octavi Comeron. Comeron indicó cómo la transformación de la condición del trabajo común había de enfocarse en el análisis de las equivalencias propuestas por las nuevas industrias respecto a los modelos laborales no industriales, o si se quiere, menos productivistas: laborar versus trabajar:

Mientras que la especialización del trabajo está esencialmente guiada por el producto acabado, cuya naturaleza requiere diferentes habilidades que han de organizarse juntas, la división de la labor, por el contrario, presupone la equivalencia de actividades que no requieren especial destreza, representando una determinada cantidad de fuerza laboral en la que distintos sujetos pueden sumarse indiferenciadamente y «comportarse como si fuesen uno». (Comeron, $2007: 25)^{5}$

Comeron consideraba que la división del trabajo, vista desde esta perspectiva, suponía lo contrario a la cooperación.

\section{Referencias (citadas)}

Aramburu, N. (ed.) (2010). «Una historia, otra, del Arte en España». Historia y situación actual de los colectivos de artistas y espacios independientes en el Estado español (1980-2010). ISBN: 978-84-614-92572. Vitoria-Gasteiz: Auto-edición, pp. 13-42.

BAdia, T. (1993). «El hecho X. De lo alternativo a los alterespacios». De Calor, $\mathrm{n}^{\mathrm{o}}$ 1, Barclona, pp. 12-16.

Baeza Medina, A. (2005). Arte colectivo neopop en el Madrid de los 90. Tesis Doctoral. ISBN: 84-669-2706-9. Madrid: Universidad Com-

5. Sobre la obra de Comeron, ver Badia, T.; Marzo, J. L.; Masó, J. (eds) (2014): No es lo más natural. Escritos y trabajos de Octavi Comeron. Barcelona: Ediciones BAU. 
plutense.

BREA, J. L. (ed.) (1992). «Oscuras paternidades. Una conversación entre Joan Brossa, Pepe Espaliú, Ferrán García Sevilla, Juan Muñoz, Cristina Iglesias y José Luis Brea». Antes y después del entusiasmo, catálogo de exposición. Amsterdam: sDu Publishers \& The Contemporary Art Foundation, pp. 157-181.

Carrillo, J. (2007). «Acords i desacords: notes per a d'altres històries de l'art contemporani a l'Estat espanyol (1976-2007)». Font, J; PERPINYÀ, M. (eds), Eufòries, desencisos i represes dissidents. L'art $i$ la crítica dels darrers vint anys. Girona: Papers d'Art, Fundació Espais d'Art Contemporani, pp. 19-39.

Comeron, O. (2007). Arte y Postfordismo. Notas desde la Fábrica Transparente. Madrid: Trama \& Fundación Arte y Derecho.

Eraso, M; Ortiz, C. (2007). «D’un espai unívoc a un espai cacofònic. A manera d'introducció». Font, J; PerpinyÀ, M. (eds), Eufòries, desencisos $i$ represes dissidents. L'art i la crítica dels darrers vint anys. Girona: Papers d'Art, Fundació Espais d'Art Contemporani, pp. 115-135.

GunTín, F. (2010). «Las asociaciones profesionales de artistas visuales en el Estado español (1980-2010)»; Aramburu, N. (ed) (2010). Historia y situación actual de los colectivos de artistas y espacios independientes en el Estado español (1980-2010). ISBN: 978-84-614-92572. Vitoria-Gasteiz: Auto-edición, pp. 43-50.

MArzo, J. L. (2007). «Mitos y realidades de las experiencias creativas colectivas». Fundación Rodríguez (ed). Estructuras, redes, colectivos. Un segmento conector. Vic: QUAM-07, H. Associació per a les Arts Contemporànies, Eumo Editorial, pp. 26-35.

Mayayo, P. (2015). «¿Un despertar de la sociedad civil»; «Arte en la esfera pública». Marzo, J. L.; MaYayo, P. Arte en España 1939-2015. Ideas, prácticas, políticas. Madrid: Cátedra: pp. $678-708$.

Rubio, P. (1991). «Ejercicios en la barra. Entrevista a Miquel Barceló». Lápiz, no 82-83, pp. 112-115; publicación original (1984), Lápiz, nº 21.

Salinas, P. (2010). «Breve apunte sobre una experiencia de gestión y difusión del arte y la cultura desde la independencia y la periferia». ARAMBURU, N. (ed) (2010). Historia y situación actual de los colectivos de artistas y espacios independientes en el Estado español (19802010). isbn: 978-84-614-9257-2. Vitoria-Gasteiz: Auto-edición, pp. 69-74.

Trigueros, C. (2010). «Sobre Colectivos de Artistas y Espacios Indepen- 
dientes para el Arte Visual en Castilla y León». Aramburu, N. (ed.) (2010). Historia y situación actual de los colectivos de artistas y espacios independientes en el Estado español (1980-2010). ISBN: 978-84-614-9257-2. Vitoria-Gasteiz: Auto-edición, pp. 79-94.

\section{Referencias}

Arrazola, T. (2012). Teoría sobre la noción de autoría, modelos colaborativos de creación e implicaciones para las prácticas y la educación del Arte Contemporáneo. Tesis doctoral. Bilbao: Universidad del País Vasco, pp. 440-824.

Blanco, P. (2005). «Prácticas colaborativas en la España de los noventa». Desacuerdos. Sobre arte, políticas y esfera pública en el arte español, $\mathrm{n}^{\mathrm{o}}$ 2. Barcelona: Arteleku-Diputación Foral de Guipúzcoa, macba y unia arteypensamiento, pp. 188-205.

Blanco, P.; Carrillo, J.; Claramonte, J. y Expósito, M. (eds.) (2001). Modos de hacer. Arte crítico, esfera pública y acción directa. Salamanca: Ediciones de la Universidad de Salamanca.

Fundación Rodríguez (ed.) (2007). Estructuras, redes, colectivos. Un segmento conector. Vic: QUAM-07, H. Associació per a les Arts Contemporànies, Eumo Editorial.

Marín García, T. (2013). «Experiencias de creación colectiva y otras prácticas artísticas colaborativas en la comunidad valenciana (19822012)». De la Calle, R. (coord.) (2013). Los últimos treinta años del Arte Valenciano Contemporáneo. Vol. 3. Valencia: Real Academia de Bellas Artes de San Carlos.

Pujals, E. (2004). «El arte de la fuga: modos de la producción artística colectiva en España, 1980-2000». Desacuerdos. Sobre arte, politicas y esfera pública en el arte español, $\mathrm{n}^{\circ}$ 1. Barcelona: Arteleku-Diputación Foral de Guipúzcoa, MACBA y UNIA arteypensamiento, pp. 152-160.

Romaní, M. (2008). «Formats expositius, pràctiques col·laboratives i narratives dissidents. Una deriva pels darrers quinze anys». FonT, J. Y PERPINYÀ, M. (eds.), Eufòries, desencisos i represes dissidents. L'art i la crítica dels darrers vint anys. Girona: Papers d'Art, Fundació Espais d'Art Contemporani, pp. 99-114. 
